\title{
Face-selective neurons in the vicinity of the human fusiform face area
}

Vadim Axelrod, PhD, Camille Rozier, PhD, Tal Seidel Malkinson, PhD, Katia Lehongre, PhD, Claude Adam, MD, PhD,
Virginie Lambrecq, MD, PhD, Vincent Navarro, MD, PhD, and Lionel Naccache, MD, PhD Neurology ${ }^{\circledR}$ 2019;92:197-198. doi:10.1212/WNL.0000000000006806

Face perception is thought to be mediated by neural activity in the occipital and posterior temporal cortex. ${ }^{1,2}$ However, the face-selective neurons at the cellular level in these areas in humans have never been demonstrated. We had a rare opportunity to record intracranial multiunit activity in an epilepsy patient near the fusiform face area ${ }^{2}$ (figure 1A). We identified 2 units with highly face-selective response to static images of familiar (famous) and unfamiliar faces (figure 1B and video 1; figure e-1a, doi.org/10.5061/dryad.81t0fq1) as well as to human and animal faces that appeared in a movie (figure $1 \mathrm{C}$, video 1 , figure $\mathrm{e}-1 \mathrm{~b}$ ).

\section{Author contributions}

V. Axelrod: conceiving the study, designing and preparing the experiments, analyzing the data, writing, editing and revising the manuscript. C. Rozier: data acquisition. T.S. Malkinson: data acquisition, editing the manuscript. K. Lehongre: responsibility for intracranial recording infrastructure, editing the manuscript. C. Adam: responsibility for intracranial recording infrastructure. V. Lambrecq: responsibility for intracranial recording infrastructure, editing the manuscript. V. Navarro: responsibility for intracranial recording infrastructure, editing the manuscript. L. Naccache: conceiving the study, supervising the project, editing the manuscript.

\section{Acknowledgment}

The authors thank the patient for participating in this study, Leila Reddy for advice on using the wave_clus tool, and Roy Export SAS for permission to use material from The Circus.

\section{Study funding}

This study was supported by an Alon Fellowship for outstanding young faculty members by the Israeli Council for Higher Education (V.A.), Israel Science Foundation (57/15) and Marie Skłodowska-Curie (702577) fellowships (T.S.M.), and the program "Investissements d'avenir" ANR-10-IAIHU-06 and the ICM-OCIRP.

\section{Disclosure}

The authors report no disclosures relevant to the manuscript. Go to Neurology.org/N for full disclosures.

\section{References}

1. Bentin S, Allison T, Puce A, Perez E, McCarthy G. Electrophysiological studies of face perception in humans. J Cogn Neurosci 1996;8: 551-565.

2. Kanwisher N, Yovel G. The fusiform face area: a cortical region specialized for the perception of faces. Philos Trans R Soc B Biol Sci 2006;361:2109-2128.

\author{
Correspondence \\ Dr. Axelrod \\ vadim.axelrod@gmail.com
}

MORE ONLINE

Video

\footnotetext{
From The Gonda Multidisciplinary Brain Research Center (V.A.), Bar Ilan University, Ramat Gan, Israel; Institut National de la Santé et de la Recherche Médicale Unité 1127 (C.R., T.S.M., K.L., V.L., V.N., L.N.), Centre National de la Recherche Scientifique Unité Mixte de Recherche (UMR) 7225, Sorbonne Université, Université Pierre-et-Marie-Curie Univ Paris 06 UMR S 1127, Institut du Cerveau et de la Moelle Épinière; Centre de Neurolmagerie de Recherche-CENIR (K.L.), Institute of Brain and Spine, UMRS 1127, CNRS UMR 7225, PitiéSalpêtriere Hospital; Epilepsy Unit and Neurophysiology Department (C.A., V.L., V.N.), AP-HP, GH Pitie-Salpêtrière-Charles Foix; and Departments of Neurology and Neurophysiology (L.N.), AP-HP, Groupe Hospitalier Pitié-Salpêtrière, Paris, France.

Go to Neurology.org/N for full disclosures.
} 
Figure Recording location and the results of unit 1

A

Blue arrows point to
implanted depth electrode
Dotted green circle is an
approximate* location of
the microwires used for
multi-unit recording
Yellow arrow points to the
individual right FFA
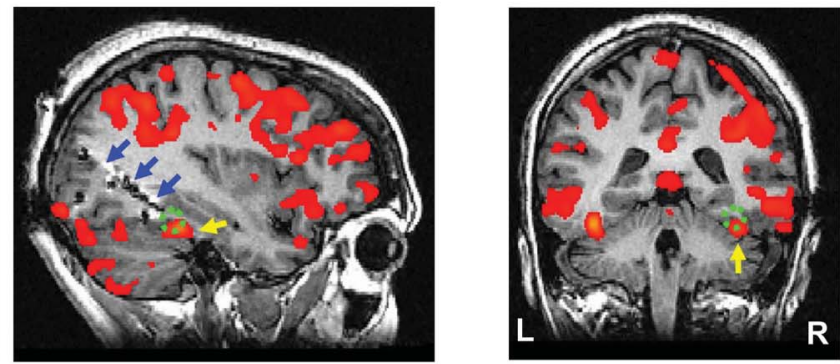

17

3.1

\section{B. Static images}
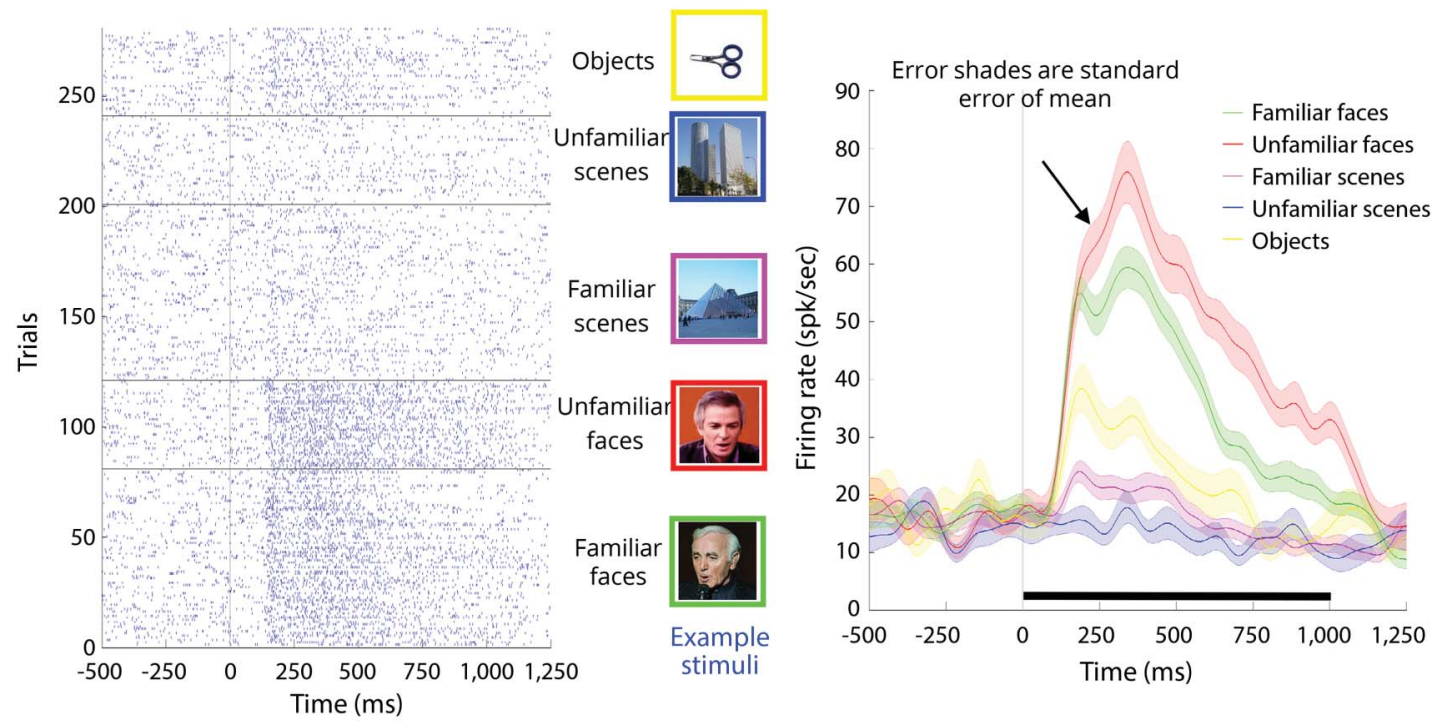

C. Movie

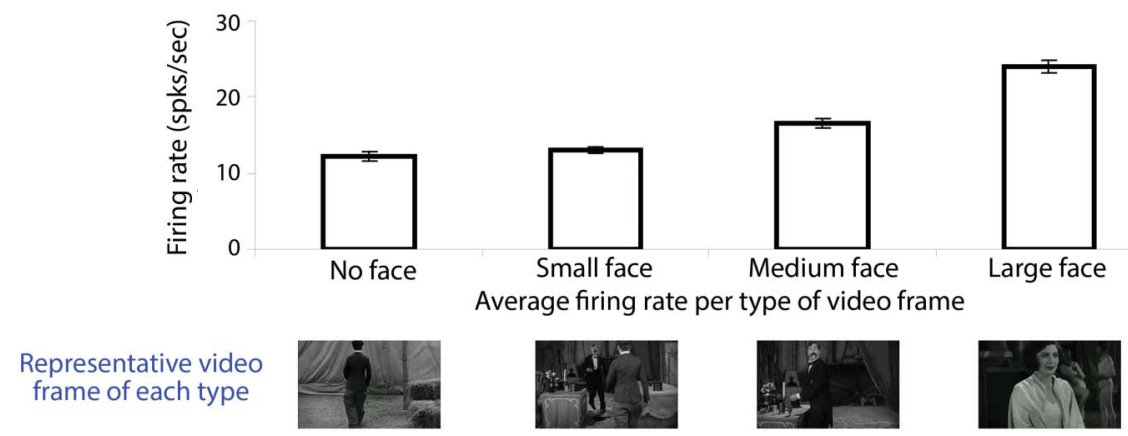

1(A) Anatomic image with overlaid individual functional MRI activations (contrast: face > objects; $p<0.001$, uncorrected). (B) Experiment with static images: left is a raster plot (horizontal gray lines separate the different conditions); right is across trials' mean instantaneous firing rate per condition. Note the high faceselectivity in both face conditions. Credits for images: unfamiliar scene: Avishai Taicher (CC BY 2.5), familiar scene: user: ewrfpiuqwnpiafnpwi (CC BY 2.5) unfamiliar face: Moshe Sinai, familiar face: shutterstock.com. (C) Movie experiment (6-minute fragment of The Circus silent film). Movie frames ( $n=1,800)$ were binned into 4 different types of frames of the movie: large, medium, small, and no faces. Note the higher average firing rate for frames with large faces. Error bars denote the standard error of mean. *Human electrophysiology does not permit us to establish unequivocally whether the units were within the boundaries of the fusiform face area (FFA; e-Methods, doi.org/10.5061/dryad.81t0fa1). Permission to reproduce material from The Circus movie: Charles Chaplin, The Circus; Copyright Roy Export SAS; all rights reserved (office@charliechapin.com). 


\section{Neurology}

\section{Face-selective neurons in the vicinity of the human fusiform face area \\ Vadim Axelrod, Camille Rozier, Tal Seidel Malkinson, et al. \\ Neurology 2019;92;197-198 \\ DOI 10.1212/WNL.0000000000006806}

This information is current as of January 21, 2019

$\begin{array}{ll}\begin{array}{l}\text { Updated Information \& } \\ \text { Services }\end{array} & \begin{array}{l}\text { including high resolution figures, can be found at: } \\ \text { http://n.neurology.org/content/92/4/197.full }\end{array} \\ \text { References } & \text { This article cites } 2 \text { articles, } 0 \text { of which you can access for free at: } \\ & \text { http://n.neurology.org/content/92/4/197.full\#ref-list-1 } \\ \text { Subspecialty Collections } & \text { This article, along with others on similar topics, appears in the } \\ & \text { following collection(s): } \\ & \text { fMRI } \\ \text { http://n.neurology.org/cgi/collection/fmri } & \text { Functional neuroimaging } \\ & \text { http://n.neurology.org/cgi/collection/functional_neuroimaging } \\ & \text { Intracranial electrodes } \\ \text { http://n.neurology.org/cgi/collection/intracranial_electrodes } & \\ & \text { Information about reproducing this article in parts (figures,tables) or in } \\ & \text { its entirety can be found online at: } \\ \text { http://www.neurology.org/about/about_the_journal\#permissions } & \text { Information about ordering reprints can be found online: } \\ \text { Permissions \& Licensing } & \text { http://n.neurology.org/subscribers/advertise }\end{array}$

Neurology ${ }^{\circledR}$ is the official journal of the American Academy of Neurology. Published continuously since 1951, it is now a weekly with 48 issues per year. Copyright @ 2019 American Academy of Neurology. All rights reserved. Print ISSN: 0028-3878. Online ISSN: 1526-632X.

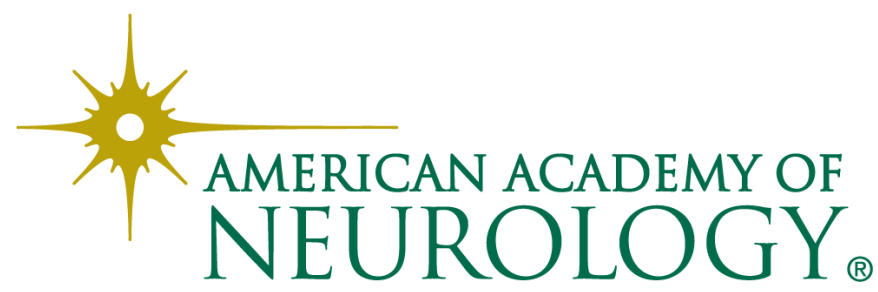

